Check for updates

Cite this: RSC Adv., 2018, 8, 18904

\title{
Mussel-inspired bio-compatible free-standing adhesive films assembled layer-by-layer with water-resistance $\uparrow$
}

\author{
Dan Wang, (iD ab Jianfu Zhang, (D)*ab Yingjie Zhong, (D)*c Ming Chu, ab \\ Wenyang Chang $^{\mathrm{a}}$ and Zhanhai Yao ${ }^{\mathrm{b}}$
}

\begin{abstract}
The development of mussel-inspired materials with enhanced mechanical and physiological characteristics is fascinating due to the resulting structural properties. In this work, based on a chemical reaction, 3-(3,4dihydroxyphenyl)propionic acid and dopamine hydrochloride (DA), with a catechol group, were covalently grafted onto a bio-compatible polymer backbone of chitosan hydrochloride (CHI) and hyaluronic acid sodium (HA). A mussel-inspired water-resistant adhesive film that could adhere in water was then fabricated by an environmentally friendly layer-by-layer ( $L b L)$ process. The water-resistant adhesive film demonstrated a strong underwater mechanical connection (0.82 $\pm 0.19 \mathrm{MPa})$ and a high transmittance (more than $83 \%$ ) in the visible region; these characteristics are beneficial for clinical observation. A freestanding water-resistant adhesive film with a high transmittance of over $83 \%$ was also demonstrated and obtained from a facial and effective mechanical exfoliation method. The free-standing film exhibited favorable adhesion capacity with porcine skin, making it attractive for applications in the biomedical field.
\end{abstract}

Received 15th April 2018 Accepted 13th May 2018

DOI: $10.1039 / c 8 r a 03214 a$

rsc.li/rsc-advances in wet environments., ${ }^{\mathbf{5 , 9 1 1}}$ The catechol group is a dominant component in the marine mussel adhesive protein, and it enables marine mussels to bind to different substrate surfaces., ${ }^{\mathbf{5 , 1 2}}$ Inspired by marine mussels, several researchers have reported adhesives with wet adhesion abilities that include catechol groups..$^{13-15}$ For example, nitro-functionalized catechol was applied to form bio-materials, which showed remarkable lighttriggered debonding and degradation. ${ }^{\mathbf{1 5}}$ In addition, adhesives with robust wet adhesion abilities were developed via the polymerization of catechol-modified monomers. Wilker and coworkers synthesized catechol-containing block polymers by controlling monomer content. These block polymers can act as underwater adhesives, with an appreciable lap shear strength of $0.4 \pm 0.2 \mathrm{MPa}^{16}$ To explore further clinical applications, Kang et al. reported self-sealing hemostatic needles with catecholfunctionalized chitosan adhesive coatings to prevent blood loss completely. ${ }^{7}$ Catechol-containing adhesives with metal coordination are also used widely in the biomedical field. ${ }^{17,18}$ To harness the specific interactions between catechol and metal ions in the mussel protein, Wilker et al. mixed 3,4-dihydroxyphenylalanine (DOPA) protein and various metals and oxidants, thereby demonstrating that oxidizing metal ions are integral for the curing of DOPA-containing proteins via cross-linking of metal and catechol. ${ }^{17}$ With regard to oxidizing metal ions, the ferric ion $\left(\mathrm{Fe}^{3+}\right)$ is widely used with catechol-containing mussel adhesive proteins, which can cross-link $\mathrm{Fe}^{3+}$ and catechol, achieving rapid adhesion. For example, Wang et al. prepared mussel mimetic polyurethane hydrogel, which can be instantaneously cured by adjusting the $\mathrm{pH}$ after contact with $\mathrm{Fe}^{3+} \cdot{ }^{19}$ 
In most work reported thus far, the controlling of viscosity of traditional glue for fluid flow during device fabrication remains challenging, especially when dispensing through a capillary using a thin film deposition processes. ${ }^{\mathbf{2 0}-24}$ An adhesive with a special shape to fit the substrate has been used instead. ${ }^{22-24}$ Generally, there are three types of medical adhesives based on their physical form: powder, gel and film. ${ }^{24}$ Adhesive films with water resistance capacity are currently popular because of their great potential and existing applications, such as for closing wounds in tissue and surgical repair. ${ }^{21-25}$ Among water-resistant adhesives, adhesive films have a unique two-dimensional structure, which is thought to provide unique advantages for biomedical applications. ${ }^{23,26-28}$ Additionally, the curing conditions of conventional biomedical adhesives are usually extreme and unfriendly to organs. ${ }^{6,29}$ Therefore, new methods are being developed to fabricate water-resistant adhesive films with the following characteristics: (a) several micrometre thickness; (b) convenient to control; (c) operational and curable in aqueous solution; (d) facile and environmentally friendly processing; (e) stable mechanical connection; and (f) biocompatibility and biodegradability. Layer-by-layer (LbL) assembly, which involves alternating substrate deposition in aqueous solution, is a versatile method to fabricate multifunctional films that are water-resistant. ${ }^{6,30-32}$ LbL assembly has drawn increasing attention because of various unique advantages, including precise control of structures and functions and ease of introducing numerous functional groups or materials into multilayer films assembled by LbL: biomacromolecules, synthetic polymers, drugs and so forth. ${ }^{33-35}$ Recent studies have demonstrated the potential applications of adhesive films assembled by LbL in a wet environment, opening a new field of modern and future adhesive films. ${ }^{31}$ Sun et al. reported a poly(allylamine hydrochloride)-dextran and hyaluronic acid sodium (HA) freestanding adhesive films to which drugs could be loaded and released, demonstrating a strong adhesion ability $(2.69 \pm 0.92$ $\mathrm{MPa}$ ) with ibuprofen-loaded free-standing adhesive films for bovine periostea. ${ }^{36}$ However, the adhesive films were limited because they were operated in air, and water molecules evaporated during the adhesion process. Traditional adhesive films assembled by LbL will weaken when they are immersed in water again, as described in our previous work. ${ }^{32}$ Incorporating a water-resistant function to a free-standing film will greatly extent the application and design area. ${ }^{37}$ Therefore, fabricating water-resistant free-standing adhesive films using the LbL assembly method will enable exploration of their use in the biomedical field.

Inspired by the distinguished water-resistant capacity of mussels, a water-resistant free-standing adhesive film was fabricated using the LbL assembly technique. For clinical applications, favorable biocompatibility is required, and formation under physiological fluids must occur without harmful components or by-product release. To prepare waterresistant free-standing adhesive films with excellent biocompatible materials, chitosan hydrochloride (CHI) and HA were used as building blocks. CHI and HA, both of which have been approved by the Food and Drug Administration (FDA), are biocompatibility and have been used in diverse biomedical applications, such as wound closure and hemostasis. ${ }^{38,39}$ Strongly adhering chitosan-containing bio-adhesives have been further developed for biomedical applications. ${ }^{7,40}$ The excellent wet adhesion ability of HA has been demonstrated when HA grafts with catechol groups. ${ }^{41}$ Here, catechol was chosen as the primary water-resistant adhesive group to ensure water resistance of both the film and the interface between the film and substrate. To graft catechol groups to CHI, 3-(3,4-dihydroxyphenyl)propionic acid was covalently grafted to $\mathrm{CHI}$ by $\mathrm{N}$-(3dimethylaminopropyl)- $N$-ethylcarbodiimide hydrochloride (EDC), named CHI-C. In addition, the carboxyl group of HA and the amino group of dopamine hydrochloride (DA) were also covalently grafted in the presence of EDC, named HA-D. The water-resistant free-standing adhesive film could be operated in water and immersed for more than $4 \mathrm{~d}$, and it displayed a high adhesion strength of $0.40 \pm 0.22 \mathrm{MPa}$, along with a transmittance of greater than $83 \%$ in the visible region. Furthermore, the water-resistant adhesive film is capable of exfoliation via blade. Overall, compared previous reports of free-standing adhesive films preparation such as organic solvents, complex synthesis or dry adhesion, this work provides a convenient and environmental friendly method to prepare free-standing adhesive films for potential applications in the biomedical field. ${ }^{\mathbf{4 2 - 4 4}}$

\section{Experimental}

\section{Materials}

HA ( $M_{\mathrm{w}} 1630$ 000), 3-(3,4-dihydroxyphenyl)propionic acid, EDC and DA were purchased from Sigma-Aldrich. CHI $\left(M_{\mathrm{w}} 200000-\right.$ 300 000) was received as a gift from Zhejiang Aoxing Biotechnology Co., Ltd. (China). Di-sodium hydrogen phosphate $\left(\mathrm{Na}_{2}-\right.$ $\mathrm{HPO}_{4} \cdot 12 \mathrm{H}_{2} \mathrm{O}$ ), sodium phosphate monobasic dihydrate $\left(\mathrm{NaH}_{2} \mathrm{PO}_{4} \cdot 2 \mathrm{H}_{2} \mathrm{O}\right)$, sodium sulfate $\left(\mathrm{Na}_{2} \mathrm{SO}_{4}\right)$ and sodium hydroxide $(\mathrm{NaOH})$ were purchased from Beijing Chemical Works (China). Ferric chloride $\left(\mathrm{FeCl}_{3}\right)$ was purchased from Tianjin Huadong Products (China). Sodium chloride ( $\mathrm{NaCl}$ ) was purchased from Tianjin DingShengXin Chemical Industry Co., Ltd. (China). Potassium chloride ( $\mathrm{KCl}$ ) was purchased from Tianjin DaMao Chemical Reagent Factory (China). The dialysis bag $\left(M_{\mathrm{W}}\right.$ 8000-14 000) was purchased from Beijing DingGuo ChangSheng Biotechnology Co., Ltd. (China). All of the chemicals were used as received without further purification. Deionized water was used in all experiments.

\section{Synthesis of the CHI-C and HA-D solutions}

CHI-C and HA-D were prepared generally according to literature. ${ }^{45,46}$ Briefly, the preparation process is as follows.

Preparation of phosphate buffered saline (PBS) (0.01 M, pH 6.0). $\mathrm{Na}_{2} \mathrm{HPO}_{4} \cdot 12 \mathrm{H}_{2} \mathrm{O}(71.6 \mathrm{~g})$ and $\mathrm{NaH}_{2} \mathrm{PO}_{4} \cdot 2 \mathrm{H}_{2} \mathrm{O}(31.2 \mathrm{~g})$ were dissolved in deionized water $(1000 \mathrm{~mL})$, respectively. Then, $\mathrm{Na}_{2} \mathrm{HPO}_{4}(12.3 \mathrm{~mL})$ and $\mathrm{NaH}_{2} \mathrm{PO}_{4}(87.7 \mathrm{~mL})$ were mixed together at a pH of 6.0, and this solution was named $0.2 \mathrm{M}$ PBS. Finally, 0.2 M PBS was diluted 20 times to obtain $0.01 \mathrm{M}$ PBS with $\mathrm{pH}$ of 6.0.

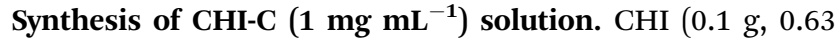
mmol) was dissolved in deionized $\mathrm{H}_{2} \mathrm{O}(50 \mathrm{~mL})$, and then, the 
pH was adjusted to 6.2 using $\mathrm{NaOH}(1 \mathrm{M})$ solution. 3-(3,4Dihydroxyphenyl)propionic acid $(0.04 \mathrm{~g}, 0.22 \mathrm{mmol})$ was dissolved in another beaker of deionized $\mathrm{H}_{2} \mathrm{O}(50 \mathrm{~mL})$. Then, EDC $(0.0717 \mathrm{~g}, 0.37 \mathrm{mmol})$ was added and stirred for at least $3 \mathrm{~h}$. Finally, they were mixed together, and the $\mathrm{pH}$ of the solution was kept at 5.0 for at least $3 \mathrm{~h}$ with $\mathrm{HCl}(1 \mathrm{M})$.

Synthesis of HA-D $\left(1 \mathbf{~ m g ~} \mathbf{m L}^{-1}\right)$ solution. HA $(0.1 \mathrm{~g}, 0.25$ $\mathrm{mmol}$ ) was dissolved in PBS solution $(100 \mathrm{~mL})$ adjusted to a $\mathrm{pH}$ of 5.0 with $\mathrm{HCl}$ solution $(1 \mathrm{M})$, and EDC $(0.0433 \mathrm{~g}, 0.23 \mathrm{mmol})$ was added, followed by stirring for at least $3 \mathrm{~h}$. Then, DA $(0.0527 \mathrm{~g}, 0.28 \mathrm{mmol})$ was added to the above reaction solution, and maintained at a $\mathrm{pH}$ of 5.0 for at least $3 \mathrm{~h}$ with $\mathrm{HCl}(1 \mathrm{M})$.

Dialysis of the CHI-C and HA-D solutions. To remove unreacted reagents and salts, the CHI-C $\left(1 \mathrm{mg} \mathrm{mL}^{-1}\right)$ and HA-D ( $1 \mathrm{mg} \mathrm{mL}^{-1}$ ) solutions were dialyzed using a dialysis bag against deionized water for $7 \mathrm{~d}$ at room temperature, and the water was changed twice a day. Importantly, the $\mathrm{pH}$ of the dialysate was maintained over 2-4 to avoid the over-oxidation of catechol. The dialysate was only applied to measure the absorbance.

\section{Preparation of water-resistant adhesive films assembled by LbL}

Glass and quartz substrates were cleaned with piranha solution (3: 7 mixture of $30 \% \mathrm{H}_{2} \mathrm{O}_{2}$ and $98 \% \mathrm{H}_{2} \mathrm{SO}_{4}$ ) and heated until no bubbles formed. Then, the substrates were rinsing with plenty of water, followed by air drying. To reach absorption saturation, the cleaned substrates were first immersed in $\mathrm{CHI}-\mathrm{C}$ solution for at least $1 \mathrm{~h}$ before preparing the film. Then, the substrates were immersed in CHI-C solution $\left(1 \mathrm{mg} \mathrm{mL}{ }^{-1}\right.$, $\mathrm{pH}$ 5.0) for $5 \mathrm{~min}$, followed by two washing steps in water (1 min each). Next, the substrates were transferred to HA-D solution (1 mg mL $\mathrm{mL}^{-1}$, pH 5.0 ) for $5 \mathrm{~min}$ and washed in the same manner. This process is called a cycle, and the prepared film is called a (CHI-C/HA-D)*n water-resistant adhesive film assembled by LbL ( $n$ represents the number of deposition cycles). The immersion and rinse processes were repeated until the desired number of cycles was achieved. For comparison, the $(\mathrm{CHI} / \mathrm{HA}) * n$ adhesive film was also fabricated via LbL assembly with $\mathrm{CHI}\left(1 \mathrm{mg} \mathrm{mL}{ }^{-1}\right.$, pH 5.0) and HA (1 mg $\mathrm{mL}^{-1}, \mathrm{pH}$ 5.0) solutions. The growth process is the same as for the (CHI-C/HA-D)* $n$ multilayer film.

\section{Preparation of free-standing films}

A convenient and facile method for the preparation of a freestanding film is applied. The (CHI-C/HA-D) ${ }^{*} n$ and $(\mathrm{CHI} / \mathrm{HA})^{*} n$ free-standing films were obtained by directly exfoliating it from the substrate with a blade in the water.

\section{Preparation of artificial seawater}

Artificial seawater was prepared by dissolving $\mathrm{NaCl}, \mathrm{KCl}$ and $\mathrm{Na}_{2} \mathrm{SO}_{4}$ in deionized $\mathrm{H}_{2} \mathrm{O}$ according to a previously discussed process (NaCl: $2.4 \mathrm{wt} \%$, KCl: $0.07 \mathrm{wt} \%$ and $\left.\mathrm{Na}_{2} \mathrm{SO}_{4}: 0.4 \mathrm{wt} \%\right) .{ }^{47}$

\section{Adhesion of water-resistant adhesive films assembled by LbL}

Two pieces of substrate deposited with multilayer films with contact areas of $5 \mathrm{~mm} \times 5 \mathrm{~mm}$ were bonded in the water. Then, a small binder clip was used on the samples to provide a constant pressure about $0.8 \mathrm{MPa}$ for the desired time. Finally, the samples were immersed in different wet environments for the required time. After the process, a supporting steel slice with a hole was bonded to substrate using commercially available modified acrylate adhesive to facilitate the following lap shear tests. When the lap shear test needs to be operated in water, a curing time of about $20 \mathrm{~min}$ in saturated humidity at room temperature was allowed to ensure that the organic solvents of the modified acrylate adhesive evaporated. Then, the bonded samples were immersed in water for at least $2 \mathrm{~h}$ to ensure that the bonded film was full of water molecules. To investigate the adhesion strength of the $(\mathrm{CHI}-\mathrm{C} / \mathrm{HA}-\mathrm{D})^{*} n$ film on the tissue surface, porcine skin was selected as substitute for human skin to carry out the lap shear strength test. To achieve effective adhesion, the grease of the porcine skin surface was scraped off with a blade. ${ }^{48}$ The porcine skins samples with a $4 \mathrm{~cm} \times 1 \mathrm{~cm}$ size were immersed in water before use. Then, the (CHI-C/HA-D)* $n$ free-standing adhesive film with a $5 \mathrm{~mm} \times 5 \mathrm{~mm}$ size was bonded with two pieces of porcine skin together in the water. To facilitate a stable connection, two pieces of steel substrate were placed on both sides of the bonded porcine skins, and then, a large binder clip was applied to provide a constant pressure about $1 \mathrm{MPa}$ for $2 \mathrm{~h}$ in the water. The pressure of the binder clip is measured by a kitchen spring scale. Compared with the traditional counterweight in our previous work, the binder clip was used in all of the experiments because it facilitated a stable connection, especially in underwater conditions. ${ }^{36}$

\section{Characterization of the water-resistant adhesive films assembled by LbL}

The cross-sections and surface morphologies of the waterresistant adhesive films were obtained via scanning electron microscopy (SEM, XL-30 ESEM FEG FEI/Phillips, Holland). The lap shear tests of adhesive films were carried out on a PT14-014 electronic universal testing machine (Changchun Great Wall Test Machine, China). The displacement rate and load change rate are $200 \mathrm{~mm} \mathrm{~min}^{-1}$ and $50 \mathrm{~N} \mathrm{~s}^{-1}$, respectively. The tensiletesting of free-standing adhesive films were tested on a materials testing (INSTRON 1121) at ambient environment. The stretching velocity was set as $20 \mathrm{~mm} \mathrm{~min}^{-1}$. The tensile strain $(\varepsilon)$ was defined as $\varepsilon=\left(l-l_{0}\right) / l_{0} \times 100 \%$ (l: length, $l_{0}$ : initial gauge length). The lap shear strengths and tensile-testing of various samples were measured at least five times in the same condition, and the data was presented as mean \pm standard deviation. The ultraviolet (UV)-visible (Vis) transmittance and absorb spectra were collected on a UV-1240 UV-Vis spectrophotometer (Shimadzu, Japan). The (CHI-C/HA-D)* $n$ film was deposited on a quartz substrate to carry out the UV test because there is no absorption in the ultraviolet region for the quartz substrate. Fourier transform infrared spectrometer (FTIR, FTIR- 
8400S, Shimadzu, Japan) was used to characterize the adhesive films structure.

\section{Results and discussion}

\section{Preparation of water-resistant adhesive films assembled by LbL}

CHI and HA have been attractive bio-materials because of their remarkable biocompatibility. ${ }^{38,39}$ There are many active functional groups in CHI and HA, and their grafting with catechol can improve the wet adhesion strength. ${ }^{\mathbf{4 1 4} 49}$ The grafting reaction, which is simple and convenient and can be operated in mild conditions, was used to synthesize the desired polymers. ${ }^{41,49}$ The reaction routes of the materials utilized to construct the water-resistant adhesive films are depicted in Fig. 1a. The solubility of CHI is low, and it is lower in PBS. Therefore, chitosan hydrochloride was used to enhance the solubility of CHI. However, the pH of the HA solution is difficult to adjust due to the high viscosity of $\mathrm{HA}$, which is sensitive to acid and base. Thus, PBS was used to stabilize the $\mathrm{pH}$ of the HA solution. The catechol-containing CHI-C and HA-D solutions were synthesized in the presence of EDC via a simple covalent linkage of 3-(3,4-dihydroxyphenyl)propionic acid and DA to the $\mathrm{CHI}$ and HA polymer backbone, respectively. Then, we selected catechol-containing CHI-C and HA-D as candidate building blocks for preparing water-resistant adhesive films using the LbL assembly method based on electrostatic interaction, as shown in Fig. 1b. ${ }^{36,50}$ The film-forming process can be controlled by the LbL assembly method, which is beneficial for practical applications. Marine mussels with many catechol groups have high viscosity. ${ }^{12}$ Thus, during the preparation of the waterresistant adhesive film, it is important to prevent the overoxidation of 3-(3,4-dihydroxyphenyl)propionic acid and DA to maintain sufficient free catechol groups in the adhesive film. ${ }^{\mathbf{5 , 5 1}}$ More significantly, free catechol groups bind to the tissue. Therefore, a water-resistant adhesive film with sufficient free catechol groups is critical to generate a high adhesion ability. In general, over-oxidation occurs when the reaction solution is basic ( $\mathrm{pH}>7.5) .{ }^{41}$ Thus, to avoid the over-oxidation of catechol at higher $\mathrm{pH}$ values, the reaction was carried out under moderate acidic conditions with pH 5.0. Finally, the (CHI-C/HAD) ${ }^{*} n$ water-resistant adhesive films assembled by LbL were

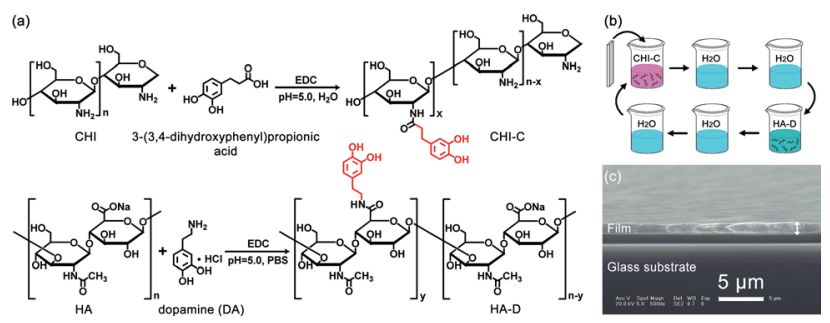

Fig. 1 (a) Synthetic routes of $\mathrm{CHI}-\mathrm{C}$ and HA-D, according to the synthetic methodology found in the literature. (b) Schematic representation of preparing water-resistant adhesive film assembled by LbL. (c) Cross-section SEM image of $(\mathrm{CHI}-\mathrm{C} / \mathrm{HA}-\mathrm{D}) * 50$ multilayer film deposited on glass substrate. fabricated, with $n$ being the number of deposition cycles. The growth process of (CHI-C/HA-D) ${ }^{*} n$ water-resistant adhesive films assembled by LbL was recorded in Fig. S1a (ESI $\dagger$ ). The average thickness of the (CHI-C/HA-D)*50 and (CHI-C/HA-D)* 150 multilayer films were calculated to be $1.30 \pm 0.06 \mu \mathrm{m}$ (Fig. 1c and S1b, ESI $\dagger$ ) and $5.87 \pm 0.15 \mu \mathrm{m}$ (Fig. S1c, ESI $\dagger$ ) from the cross-section SEM images, respectively. A gap was observed between the film and substrate, because the film was easy to separate from the substrate in the vacuum process during SEM measurement. The SEM images in Fig. S1 (ESI $\dagger$ ) shown that, with the thickness increasing, (CHI-C/HA-D)*150 multilayer film was more rough and fluctuated than (CHI-C/HA-D)*50 multilayer film.

To determine whether the $(\mathrm{CHI}-\mathrm{C} / \mathrm{HA}-\mathrm{D}) * n$ water-resistant adhesive film assembled by LbL possessed catechol groups, a UV test was performed. As shown in Fig. 2, the UV-Vis absorption spectrum of a (CHI-C/HA-D)* $n$ water-resistant adhesive film assembled by $\mathrm{LbL}$ revealed a characteristic absorption peak of catechol at $280 \mathrm{~nm}$, indicating the successful introduction of catechol groups. The grafting ratio of 3-(3,4dihydroxyphenyl)propionic acid to $\mathrm{CHI}$ was determined by employing a UV-Vis spectrophotometer to measure the absorbance of CHI-C solutions at $280 \mathrm{~nm}$ and compare them with known concentrations. Then, it was calculated from the calibration curve of 3-(3,4-dihydroxyphenyl)propionic acid (Fig. S2a and $\mathrm{b}, \mathrm{ESI} \dagger)$. A standard curve was obtained by measuring the absorbance of a series of 3-(3,4-dihydroxyphenyl)propionic acid solutions with different concentrations (from 0.004 to $0.128 \mathrm{mmol} \mathrm{L}^{-1}$ ) at $280 \mathrm{~nm} .^{8,41}$ Finally, the grafting ratio of CHI$\mathrm{C}$ was calculated to be about $3.40 \%$. In the same manner, the grating ratio about $5.16 \%$ of HA-D was also obtained (Fig. S2c and d, ESI $\dagger$ ), in accordance to previous reports. ${ }^{\mathbf{8 , 4 1}}$

\section{Adhesion properties of water-resistant adhesive films assembled by $\mathbf{L b L}$}

As in marine mussels, synthetic catechol-containing polymers can achieve underwater adhesion. ${ }^{52}$ To illustrate the underwater adhesion performance of fabricated (CHI-C/HA-D)* $n$ multilayer films, the adhesive film was subjected to a lap shear test with a mechanical testing machine. As shown in Fig. 3a, two

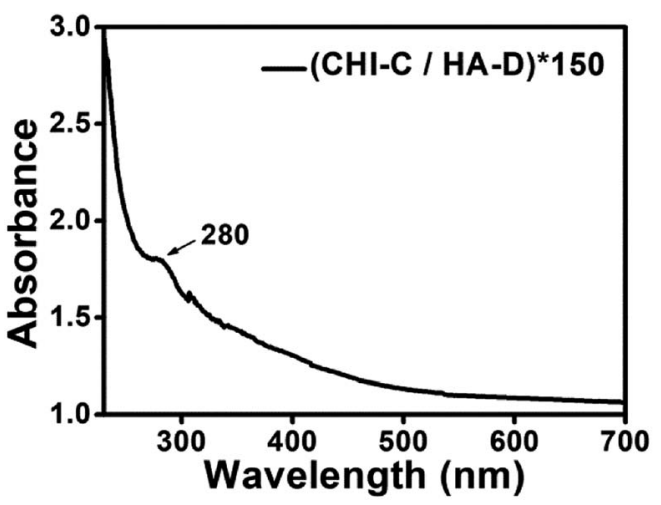

Fig. 2 UV absorption spectrum of a (CHI-C/HA-D)*150 film assembled by LbL deposited on a quartz substrate. 


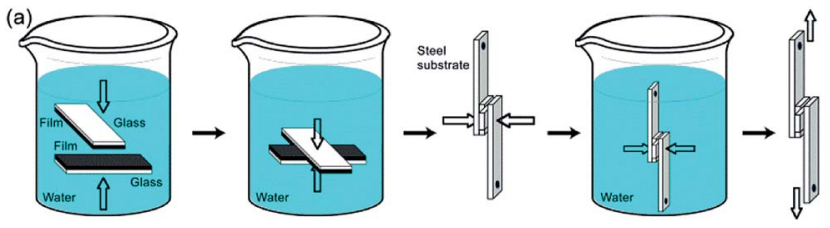

(b)
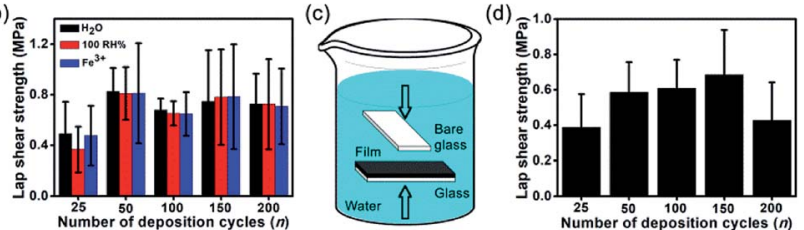

Fig. 3 (a) Schematic representation of bonding and lap shear testing processes. (b) Lap shear strengths of $(\mathrm{CHI}-\mathrm{C} / \mathrm{HA}-\mathrm{D}){ }^{*} n$ assembled by LbL water-resistant adhesive films assembled by LbL with different numbers of cycles after immersion in $\mathrm{H}_{2} \mathrm{O}, 100 \% \mathrm{RH}$ and $\mathrm{FeCl}_{3}$ solution for $4 \mathrm{~d}$. (c) Schematic representation of one-sided bonding. (d) One-sided lap shear strengths of $(\mathrm{CHI}-\mathrm{C} / \mathrm{HA}-\mathrm{D}) * n$ water-resistant adhesive films assembled by LbL with different numbers of cycles, after immersion in $\mathrm{H}_{2} \mathrm{O}$.

adhesive films deposited on glass substrates were bonded together, with a contact area of $5 \mathrm{~mm} \times 5 \mathrm{~mm}$, and then clamped with small binder clip underwater to be close to the actual application. Water and pressure facilitated polyelectrolyte diffusion. ${ }^{53}$ All the experiments were operated in water, and the water does not act as a surface contaminant, in contrast with traditional adhesive pastes. The wet adhesion property is conductive to practical biomedical application and operation. Two pieces of bonded glass substrate were deposited with water-resistant film (with catechol) assembled by LbL, and then they were immersed in deionized water, without additional curing agents. To maintain the hydration of the film, the adhesion strength was determined in water and under saturated humidity $(100 \% \mathrm{RH})$. To determine whether the crosslinking between catechol groups and metal ions affected the adhesion strength, a $\mathrm{FeCl}_{3}$ solution $\left(5 \times 10^{-4} \mathrm{~mol} \mathrm{~L}^{-1}\right)$ was tested. Then, samples were stored in these different conditions for 4 d, respectively. As shown in Fig. 3b, the (CHI-C/HA-D)* $n$ multilayer film exhibited excellent wet adhesion strength, and the maximum lap shear strength reached $0.82 \pm 0.19 \mathrm{MPa}$ for the bonded (CHI-C/HA-D)*50 multilayer film immersed in water, indicating that a contact area of $5 \mathrm{~mm} \times 5 \mathrm{~mm}$ could hold a weight of $8.2 \mathrm{~kg}$. This high value was 4.8 times higher than that measured in living mussels, which have an average adhesion of $0.17 \pm 0.07 \mathrm{MPa}$ on a glass substrate surface. ${ }^{54} \mathrm{In}$ addition, adhesion strengths of $0.81 \pm 0.21 \mathrm{MPa}$ and $0.81 \pm$ $0.40 \mathrm{MPa}$ were observed after storage in saturated humidity and a $\mathrm{FeCl}_{3}$ solution, respectively, which was similar to immersion in $\mathrm{H}_{2} \mathrm{O}$. This suggested that the adhesion strength was affected by cross-linking between catechol groups and $\mathrm{Fe}^{3+}$ in this system. It was also noted that the adhesion strength increased at first and then slightly decreased until almost the same after $n$ $=150$. While the adhesive film grafted with catechol groups possessed remarkable tissue adhesiveness, there were no obvious differences between the adhesion strengths of waterresistant films assembled by LbL with different numbers of cycles. Satisfactory adhesion strength was achieved with an appropriate thickness range: $5.87 \pm 0.15 \mu \mathrm{m}$ was thick enough for stable adhesion. To simulate a marine environment, artificial seawater was prepared to evaluate adhesion strength. The adhesion strength of the (CHI-C/HA-D)*150 multilayer film was $0.28 \pm 0.13 \mathrm{MPa}$. These results also showed that the fabricated $(\mathrm{CHI}-\mathrm{C} / \mathrm{HA}-\mathrm{D})^{*} n$ multilayer films possessed wet adhesion abilities, similar to previous reports of bonded films immersed in water. ${ }^{32}$ In addition, to explore the adhesion strength without water, the bonded (CHI-C/HA-D)*150 multilayer film was stored in air (with a humidity of $30-70 \%$ ) for $4 \mathrm{~d}$. A decreased adhesion strength of $0.63 \pm 0.14 \mathrm{MPa}$ was observed. Therefore, water is vital to the adhesion of the multilayer film. In addition, an alkaline aqueous solution of $\mathrm{pH} 9.0$ was chosen to evaluate the adhesion properties of the (CHI-C/HA-D)*150 multilayer film. The results indicated that the (CHI-C/HA-D)*150 multilayer film had decreased adhesion strength, $0.60 \pm 0.32 \mathrm{MPa}$, after immersion in $\mathrm{pH} 9.0 \mathrm{H}_{2} \mathrm{O}$ for $4 \mathrm{~d}$. The increased $\mathrm{OH}^{-}$concentration led to over-oxidation and reduced activity of catechol, diminishing the mechanical performance of water-resistant adhesive films. For comparison, the $(\mathrm{CHI} / \mathrm{HA}) * 150$ multilayer film with thickness of $4.04 \pm 0.09 \mu \mathrm{m}$ (Fig. S3, ESI $\dagger$ ) was prepared and immersed in water for $2 \mathrm{~d}$ to ensure that the film was fully saturated, and then the bonded $(\mathrm{CHI} / \mathrm{HA}) * 150$ multilayer film was immersed in water for $2 \mathrm{~d}$. The adhesion strength of the $(\mathrm{CHI} / \mathrm{HA}) * 150$ multilayer film, with a value of $0.39 \pm$ $0.26 \mathrm{MPa}$, was less than that of the (CHI-C/HA-D)*150 multilayer film, as the catechol groups disappeared. The catechol moieties improved the adhesiveness of the film. Based on these results, these fabricated water-resistant adhesive films have potential in biomedical applications.

One-sided adhesion was identified as bonding between a substrate deposited with an adhesive film and another blank substrate, which is sometimes convenient in the bonding process of materials. The one-sided bonding process of the samples is shown in Fig. 3c. (CHI-C/HA-D) ${ }^{*} n$ adhesive films deposited on glass substrates were bonded to a blank glass substrate in the presence of water and pressure (small binder clip) and then immersed in water for $4 \mathrm{~d}$. The underwater adhesion strengths of (CHI-C/HA-D) ${ }^{*} n$ adhesive films were analyzed in Fig. 3d. The results indicated that a film thickness of $5.87 \pm 0.15 \mu \mathrm{m}$ was sufficient to achieve stable one-sided adhesion, with the highest adhesion strength of $0.68 \pm$ $0.25 \mathrm{MPa}$. It is conceivable that the contact efficiency became saturated with increasing thickness as a result of fewer defects, including voids and microcracks in the film, which led to the highest adhesion strength. ${ }^{55-57}$ These results also implied that a facile LbL assembly method achieved tunable underwater oneside adhesion strengths by adjusting the deposition cycles, $n$, which also suggests the possibility of bonding different substrates.

\section{Optical analysis of water-resistant adhesive films assembled by LbL}

Recently, adhesives that are transparent in the visible region, have become particularly important in clinical observations. 
However, wet environments are inevitable in clinical application. Thus, the transmittance of a (CHI-C/HA-D)*150 multilayer adhesive film deposited on a glass substrate, before and after bonding in water, was characterized by a UV-Vis spectrum collected with air as a baseline (Fig. 4). The glass substrate with the one-sided deposition of a (CHI-C/HA-D)*150 multilayer adhesive film was bonded in the presence of water and pressure (generated by a small binder clip), and the bonded sample was immersed in water overnight. Then, the sample was tested within $10 \mathrm{~min}$ in the air. The transmittance of the glass substrate deposited with the (CHI-C/HA-D)*150 multilayer adhesive film was less than that of the bonded (CHI-C/HA-D)* 150 film, because the surface of the (CHI-C/HA-D)*150 multilayer adhesive film was rough. Strong scattering occurs when light hits the surface of a multilayer film, and thus the transmittance of the (CHI-C/HA-D)*150 multilayer film was low, corresponding with SEM images. When the samples were bonded together in the presence of water and slight pressure, the transmittance was greater than $88 \%$ in the visible region because water improved the mobility of the multilayer film and made the film bond together on the interfaces, removing the gap between the two films. Hence, reduced light scattering has a higher transmittance. The inset in Fig. 4 displays the bonded glass substrate, and the background is clearly observed. Although the unbonded section was immersed in water, the transmittance was poor due to the absence of pressure. Therefore, the prepared CHI-C/HA-D multilayer adhesive film indicated potential applications in biomedicine, such as medical dressings.

\section{Preparation of (CHI-C/HA-D) $\boldsymbol{n}$ free-standing adhesive films}

The LbL assembly method can be used to form multifunctional films. Some films cannot be immersed in aqueous solutions for long periods of time, but a stable film is desired for many

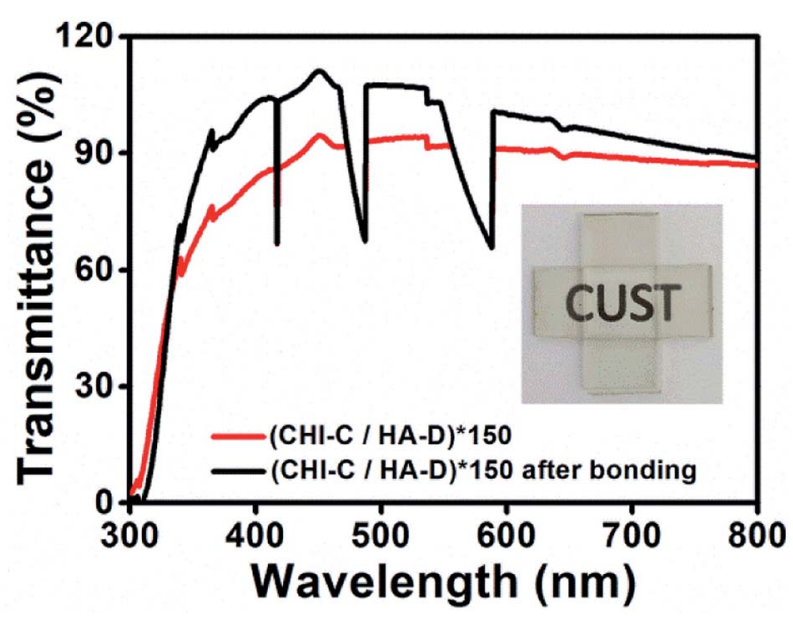

Fig. 4 UV-Vis transmittance spectra for the glass substrate upon which (CHI-C/HA-D)*150 water-resistant adhesive film assembled by LbL was deposited, and glass substrate bonded with (CHI-C/HA-D)* 150 water-resistant adhesive film assembled by LbL, using air as the baseline. Insert shows bonded glass substrate deposited with (CHI-C) HA-D)*150 multilayer film. applications. ${ }^{32}$ Free-standing films, separate from a substrate, are important in the biomedical field because the influence of the substrate can be eliminated. ${ }^{44}$ Several methods, such as dissolving the substrate or a sacrificial layer, have been demonstrated to generate free-standing films. ${ }^{58-60}$ However, the integrity of the free-standing film must be maintained during substrate removal, that is, effects on structure and performance should be avoided.

A free-standing adhesive film was successfully fabricated by a simple mechanical exfoliation method (Video S1, ESI $\dagger$ ). The (CHI-C/HA-D)* $n$ free-standing film can be fabricated in water or in air. Compared with air, water improved the mobility of the molecular chains, making the (CHI-C/HA-D) $* n$ multilayer film more flexible and giving it the ability to form a large, defect-free, free-standing film. ${ }^{61}$ Using direct exfoliation from the glass substrate with a blade in water, a large-area and defect-free $(\mathrm{CHI}-\mathrm{C} / \mathrm{HA}-\mathrm{D}) * 150$ free-standing film $(4 \mathrm{~cm} \times 4 \mathrm{~cm})$ was obtained (Fig. 5). The cross-section of the (CHI-C/HA-D)*150 freestanding film was not flat, in accordance with the (CHI-C/HAD)*150 multilayer film deposited on a glass substrate (Fig. 5c). The background was clearly visible through the free-standing film. The UV test demonstrated that the transmittance of the (CHI-C/HA-D)*150 free-standing film was over 83\% (Fig. 5d). A larger free-standing film could be obtained, depending on the size of the substrate. The adhesive film can also be peeled based on: (a) a weaker interaction between the multilayer film and glass substrate; (b) excellent water retaining properties of HA, ensuring that the multilayer film will not be broken; and (c) the interaction between the catechol groups: the multilayer film demonstrates favorable mechanical performance. Compared with using harsh solvents or applying a sacrificial layer, the direct exfoliation process was a green route and eliminated the influence of solvents on the functionality of multilayer films.

An FTIR test was employed to demonstrate the chemical structures of catechol-modified (CHI-C/HA-D)* $n$ water-resistant (a)
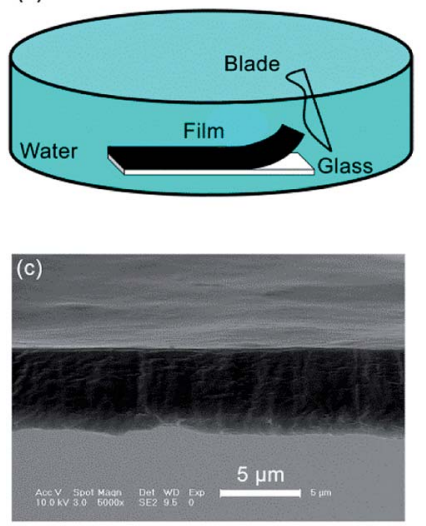

(b)
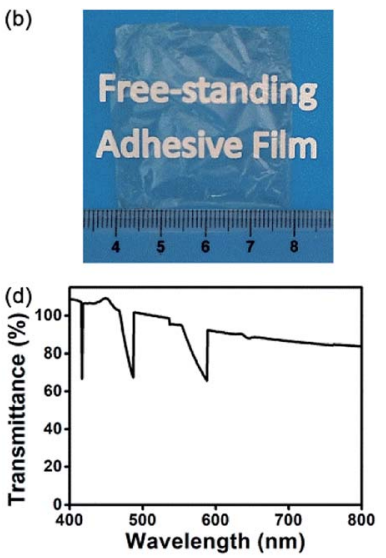

Fig. 5 (a) Schematic representation of the exfoliation process of the $(\mathrm{CHI}-\mathrm{C} / \mathrm{HA}-\mathrm{D}) * n$ free-standing film between the film and glass substrate. (b) Photograph of (CHI-C/HA-D)*150 free-standing film with a size of $4 \mathrm{~cm} \times 4 \mathrm{~cm}$. (c) Cross-section SEM image of the $(\mathrm{CHI}-$ $\mathrm{C} / \mathrm{HA}-\mathrm{D}) * 150$ free-standing film. (d) Transmittance of (CHI-C/HA-D)* 150 free-standing film, with air as the baseline. 
adhesive films assembled by LbL. Fig. S4 (ESI $\dagger$ ) exhibits the FTIR spectra of (CHI/HA)*150 and (CHI-C/HA-D)*150 freestanding films. Compared to the spectrum of the $(\mathrm{CHI} / \mathrm{HA})^{*}$ 150 free-standing film $\left(1080 \mathrm{~cm}^{-1}\right.$ and $1606 \mathrm{~cm}^{-1}$ for saccharide rings and carboxylate, respectively), ${ }^{42}$ that of the (CHI-C/HA-D)* 150 free-standing film included the characteristic band of catechol $\left(1080 \mathrm{~cm}^{-1}\right.$ for the benzene ring and $1606 \mathrm{~cm}^{-1}$ for $-\mathrm{C}-$ $\mathrm{OH}$, more intense peak than (CHI/HA ${ }^{*} 150$ free-standing film). After DA and 3-(3,4-dihydroxyphenyl)propionic acid grafting, an amide bond formed between the amine group and carboxyl group, indicated by the strong and clear characteristic band of $\mathrm{C}=\mathrm{O}$ at $1699 \mathrm{~cm}^{-1}$. Overall, the FTIR test demonstrated the presence of catechol groups in the (CHI-C/HA-D)*150 multilayer films.

\section{Adhesive properties of (CHI-C/HA-D $)^{*} \boldsymbol{n}$ free-standing adhesive films}

The previous discussions clearly indicate a higher strength of (CHI-C/HA-D)*150 multilayer films immersed in water. To assess the underwater mechanical properties of (CHI-C/HA-D)* $n$ free-standing films, a $5 \mathrm{~mm} \times 5 \mathrm{~mm}$ free-standing film was bonded with two pieces of blank glass substrate in the presence of water and pressure (Fig. 6a). Then, it was immersed in water for $4 \mathrm{~d}$. The (CHI-C/HA-D)*25 adhesive film had a relatively lower free-standing capacity compared to other adhesive films with a higher $n$. Thus, a (CHI-C/HA-D) $* n$ free-standing film with $n>50$ underwent an underwater lap shear test. As shown in Fig. $6 \mathrm{~b}$, the maximum adhesion strength was $0.40 \pm 0.22 \mathrm{MPa}$ for the (CHI-C/HA-D)*150 free-standing film. In addition, bonded samples with partial cracking were observed for $n=50$ and 200. Thus, the (CHI-C/HA-D)*150 free-standing film can maintain a stable mechanical connection.

To investigate the use of the prepared adhesive film as a medical dressing, the (CHI-C/HA-D)*150 free-standing film was adhered onto porcine skin and fresh porcine heart, and the adhesion strength was measured. We chose porcine skin as a substitute for human skin due to comparable general thickness, structure, collagenous tissue framework structure, and composition of the lipid film on the skin surface. The porcine skin bonded to a $5 \mathrm{~mm} \times 5 \mathrm{~mm}(\mathrm{CHI}-\mathrm{C} / \mathrm{HA}-\mathrm{D}) * 150$ freestanding film was stable in a shaking environment, as shown in Video S2 (ESI $\dagger$ ), and the lap shear strength was tested to be $44.48 \pm 9.79 \mathrm{kPa}$. Although the adhesion strength of the (CHI-C/
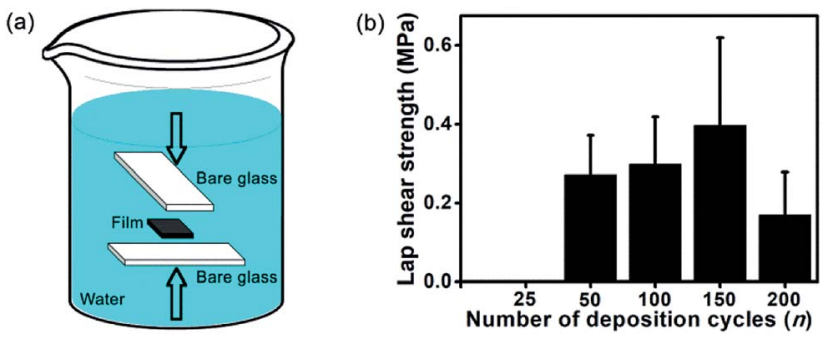

Fig. 6 (a) Schematic representation of (CHI-C/HA-D)*n free-standing film bonded with blank glass. (b) Lap shear strengths of the $(\mathrm{CHI}-\mathrm{C})$ HA-D)*n free-standing films bonded with blank glass.

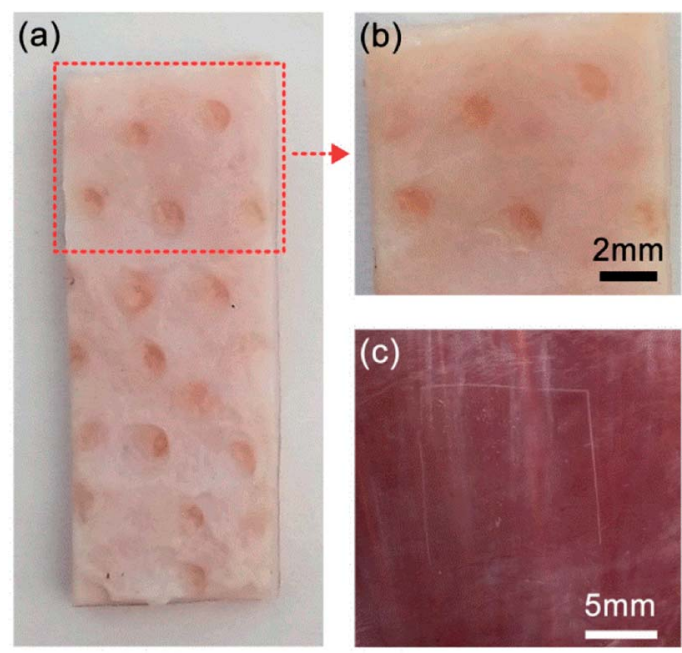

Fig. 7 (a) Porcine skin bonded with the (CHI-C/HA-D)*150 freestanding film in water for $2 \mathrm{~h}$ after separation; (b) enlarged (a). (c) Photograph of $(\mathrm{CHI}-\mathrm{C} / \mathrm{HA}-\mathrm{D}) * 150$ free-standing film attached to a fresh porcine heart.

HA-D)*150 free-standing film was relatively low compared to our previous results, the adhesion strength in our study is comparable with that of commercially available fibrin glues (0.002-0.040 MPa). ${ }^{29}$ After the bonded porcine skins were separated, the free-standing film bonded closely onto one of the porcine skins, and the surface details of the porcine skin were clear, enabling convenient observation for clinical applications (Fig. 7a and b). Furthermore, the free-standing film attached tightly to the fresh porcine heart, as shown in Fig. 7c. Tensiletesting results of dry and full swelling (immersing in water for $4 \mathrm{~d}$ ) free-standing adhesive films demonstrated high mechanical properties with $7.59 \%$ and $25.40 \%$ elongation at break, $66.87 \pm 23.06 \mathrm{MPa}$ and $1.37 \pm 0.29 \mathrm{MPa}$ tensile strength, respectively (Fig. S5, ESI $\dagger$ ). Compared to the thin $(5.87 \pm 0.15$ $\mu \mathrm{m}$ ) film derived from the LbL assembly method, the (CHI-C/ HA-D)*150 free-standing film with high mechanical properties had excellent tissue adhesion strength to tissue after bonding in a wet environment, which clearly demonstrates potential applications in biomedical systems, such as in the coating of various surfaces and medical dressings, where strength is required. These results also demonstrated LbL assembled film can be used as water-resistant adhesive films by structure design and molecular regulation. It should be noted that the loading and release of functional small drugs by adhesive films, assembled by $\mathrm{LbL}$, has been demonstrated in detail. ${ }^{36,61-64}$ Therefore, all these capabilities make the fabricated waterresistant free-standing adhesive films a promising biomedical material.

\section{Conclusions}

In summary, we demonstrated an efficient strategy using an environmentally friendly LbL process to prepare water-resistant adhesive films by simply grafting catechol onto a biocompatible polymer backbone. It is easy to tailor the structure 
and materials during the LbL assembly process as well, which makes it a promising candidate for constructing multifunctional adhesive films. A (CHI-C/HA-D)* $n$ water-resistant adhesive film with stable underwater mechanical connection $(0.82 \pm$ $0.19 \mathrm{MPa}$ ) and high transmittance (more than $83 \%$ ) in the visible region was successfully prepared. The (CHI-C/HA-D)*150 water-resistant adhesive film, with a thickness of $5.87 \pm 0.15$ $\mu \mathrm{m}$, achieved stable two-sided and one-sided adhesion. Furthermore, a facial mechanical exfoliation method was utilized to obtain a free-standing film, which maintained underwater adhesion function $(0.40 \pm 0.22 \mathrm{MPa})$ and was able to bond with porcine skin, which is an ideal mimic of human skin. Meanwhile, the free-standing film demonstrated excellent transmittance, over $83 \%$ in the visible region, and it was not affected by bonding with porcine skin. These results demonstrated a new method for designing various functional adhesives and open a new avenue for biomedical applications, such as medical dressings and wound repair.

\section{Conflicts of interest}

There are no conflicts to declare.

\section{Acknowledgements}

We greatly appreciate the financial support from the National Natural Science Foundation of China (21504008), Science and Technology Department of Jilin Province (20170520151JH), and National Key Program of Research and Development of China (2016YFB0302401).

\section{References}

1 A. Mahdavi, L. Ferreira, C. Sundback, J. W. Nichol, E. P. Chan, D. J. D. Carter, C. J. Bettinger, S. Patanavanich, L. Chignozha, E. Ben-Joseph, A. Galakatos, H. Pryor, I. Pomerantseva, P. T. Masiakos, W. Faquin, A. Zumbuehl, S. Hong, J. Borenstein, J. Vacanti, R. Langer and J. M. Karp, Proc. Natl. Acad. Sci. U. S. A., 2008, 105, 2307.

2 D. G. Barrett, G. G. Bushnell and P. B. Messersmith, Adv. Healthcare Mater., 2013, 2, 745.

3 S. Azevedo, A. M. S. Costa, A. Andersen, I. S. Choi, H. Birkedal and J. F. Mano, Adv. Mater., 2017, 29, 1700759.

4 W. Chen, R. Wang, T. T. Xu, X. B. Ma, Z. Yao, B. Chi and H. Xu, J. Mater. Chem. B, 2017, 5, 5668.

5 P. K. Forooshani and B. P. Lee, J. Polym. Sci., Part A: Polym. Chem., 2017, 55, 9.

6 V. Bhagat and M. L. Becker, Biomacromolecules, 2017, 18, 3009.

7 M. Shin, S.-G. Park, B.-C. Oh, K. Kim, S. Jo, M. S. Lee, S. S. Oh, S.-H. Hong, E.-C. Shin, K.-S. Kim, S.-W. Kang and H. Lee, Nat. Mater., 2017, 16, 147.

8 R. Wang, J. Z. Li, W. Chen, T. T. Xu, S. F. Yun, Z. Xu, Z. Q. Xu, T. Sato, B. Chi and H. Xu, Adv. Funct. Mater., 2017, 27, 1604894.

9 B. K. Ahn, J. Am. Chem. Soc., 2017, 139, 10166.
10 K. Zhang, F. L. Zhang, Y. Y. Song, J.-B. Fan and S. T. Wang, Chin. J. Chem., 2017, 35, 811.

11 J. J. Wilker, Science, 2015, 349, 582.

12 M. Yu, J. Hwang and T. J. Deming, J. Am. Chem. Soc., 1999, 121, 5825.

13 Y. H. Zhao, Y. Wu, L. Wang, M. M. Zhang, X. Chen, M. J. Liu, J. Fan, J. Q. Liu, F. Zhou and Z. K. Wang, Nat. Commun., 2017, 8, 1 .

14 W. Wei, L. Petrone, Y. Tan, H. Cai, J. N. Israelachvili, A. Miserez and J. H. Waite, Adv. Funct. Mater., 2016, 26, 3496.

15 Z. Shafiq, J. Cui, L. Pastor-Pérez, V. San Miguel, R. A. Gropeanu, C. Serrano and A. del Campo, Angew. Chem., Int. Ed., 2012, 51, 4332.

16 J. D. White and J. J. Wilker, Macromolecules, 2011, 44, 5085. 17 M. J. Sever, J. T. Weisser, J. Monahan, S. Srinivasan and J. J. Wilker, Angew. Chem., Int. Ed., 2004, 43, 448.

18 N. Holten-Andersen, M. J. Harrington, H. Birkedal, B. P. Lee, P. B. Messersmith, K. Y. C. Lee and J. H. Waite, Proc. Natl. Acad. Sci. U. S. A., 2011, 108, 2651.

19 P. Y. Sun, J. Wang, X. Yao, Y. Peng, X. X. Tu, P. F. Du, Z. Zheng and X. L. Wang, ACS Appl. Mater. Interfaces, 2014, 6, 12495.

20 F. H. Silver, M. C. Wang and G. D. Pins, Biomaterials, 1995, 16, 891.

21 H. T. Peng and P. N. Shek, Expert Rev. Med. Devices, 2010, 7, 639.

22 K. Al-Hezaimi, M. Al-Askar, Z. Selamhe, J. H. Fu, I. A. Alsarra and H.-L. Wang, J. Periodontol., 2011, 82, 963.

23 T. D. Gomes, S. G. Caridade, M. P. Sousa, S. Azevedo, M. Y. Kandur, E. T. Öner, N. M. Alves and J. F. Mano, Acta Biomater., 2018, 69, 183.

24 A. P. Duarte, J. F. Coelho, J. C. Bordado, M. T. Cidade and M. H. Gil, Prog. Polym. Sci., 2012, 37, 1031.

25 B. Ayhan, M. Erikoglu, S. S. Tavlı and H. Toy, Clin. Invest. Med., 2012, 35, E216.

26 S. Zhang, Y. Sunami and H. Hashimoto, Nanomaterials, 2017, 7, 246.

27 L. J. R. Foster and E. Karsten, J. Visualized Exp., 2012, 68, e3527.

28 S. Takeoka, Y. Okamura, T. Fujie and Y. Fukui, Pure Appl. Chem., 2008, 80, 2259.

29 R. A. Chivers and R. G. Wolowacz, Int. J. Adhes. Adhes., 1997, 17, 127.

30 D. D. Li, K. F. Ren, H. Chang, H. B. Wang, J. L. Wang, C. J. Chen and J. Ji, Langmuir, 2013, 29, 14101.

31 C. Li, Y. Q. Gu and N. S. Zacharia, ACS Appl. Mater. Interfaces, 2018, 10, 7401.

32 D. Wang, J. F. Zhang, Y. Y. He, W. F. Li, S. T. Li, X. H. Fu, M. Tian, Y. Zhou and Z. H. Yao, Macromol. Chem. Phys., 2018, 219, 1700608.

33 G. Decher, Science, 1997, 277, 1232.

34 X. Zhang, H. Chen and H. Y. Zhang, Chem. Commun., 2007, 14, 1395.

35 G. K. Such, A. P. R. Johnston and F. Caruso, Chem. Soc. Rev., 2011, 40, 19.

36 J. F. Zhang, D. D. Chen, Y. Li and J. Q. Sun, Polymer, 2013, 54, 4220. 
37 V. Mogal, V. Papper, A. Chaurasia, G. Feng, R. Marks and T. Steele, Macromol. Biosci., 2014, 14, 478.

38 H. J. Li, C. Hu, H. J. Yu and C. Z. Chen, RSC Adv., 2018, 8, 3736.

39 C. B. Highley, G. D. Prestwich and J. A. Burdick, Curr. Opin. Biotechnol., 2016, 40, 35.

40 N. Mohan, P. V. Mohanan, A. Sabareeswaran and P. Nair, Int. J. Biol. Macromol., 2017, 104, 1936.

41 J. Shin, J. S. Lee, C. Lee, H.-J. Park, K. Yang, Y. Jin, J. H. Ryu, K. S. Hong, S.-H. Moon, H.-M. Chung, H. S. Yang, S. H. Um, J.-W. Oh, D.-I. Kim, H. Lee and S.-W. Cho, Adv. Funct. Mater., 2015, 25, 3814.

42 S. G. Caridade, C. Monge, F. Gilde, T. Boudou, J. F. Mano and C. Picart, Biomacromolecules, 2013, 14, 1653.

43 L. Han, Z. M. Wang, X. Lu, L. Dong, C. M. Xie, K. F. Wang, X. L. Chen, Y. H. Ding and L. T. Weng, Colloids Surf., B, 2015, 126, 452.

44 D. D. Chen, M. D. Wu, J. Chen, C. Q. Zhang, T. Z. Pan, B. Zhang, H. Y. Tian, X. S. Chen and J. Q. Sun, Langmuir, 2014, 30, 13898.

45 H. Lee, Y. Lee, A. R. Statz, J. Rho, T. G. Park and P. B. Messersmith, Adv. Mater., 2008, 20, 1619.

46 A. L. Carvalho, A. C. Vale, M. P. Sousa, A. M. Barbosa, E. Torrado, J. F. Mano and N. M. Alves, J. Mater. Chem. B, 2016, 4, 5385.

47 J. N. Guo, C. Yuan, M. Y. Guo, L. Wang and F. Yan, Chem. Sci., 2014, 5, 3261.

48 L. Ninan, J. Monahan, R. L. Stroshine, J. J. Wilker and R. Shi, Biomaterials, 2003, 24, 4091.

49 J. H. Ryu, Y. Lee, W. H. Kong, T. G. Kim, T. G. Park and H. Lee, Biomacromolecules, 2011, 12, 2653.
50 S. S. Shiratori and M. F. Rubner, Macromolecules, 2000, 33, 4213.

51 A. R. Narkar, B. Barker, M. Clisch, J. F. Jiang and B. P. Lee, Chem. Mater., 2016, 28, 5432.

52 F. Scognamiglio, A. Travan, M. Borgogna, I. Donati, E. Marsich, J. W. A. M. Bosmans, L. Perge, M. P. Foulc, N. D. Bouvy and S. Paoletti, Acta Biomater., 2016, 44, 232.

53 D. Matsukuma, T. Aoyagi and T. Serizawa, Langmuir, 2009, 25, 9824.

54 J. R. Burkett, J. L. Wojtas, J. L. Cloud and J. J. Wilker, J. Adhes., 2009, 85, 601.

55 K. Machalická and M. Eliášová, Int. J. Adhes. Adhes., 2017, 72, 10.

56 L. F. M. Da Silva, T. N. S. S. Rodrigues, M. A. V. Figueiredo, M. F. S. F. De Moura and J. A. G. Chousal, J. Adhes., 2006, 82, 1091.

57 A. Moradi, D. Leguillon and N. Carrère, Eng. Fract. Mech., 2013, 114, 55.

58 A. A. Mamedov and N. A. Kotov, Langmuir, 2000, 16, 5530.

59 C. Y. Bao, B. H. Ma, J. L. Liu, Z. N. Wu, H. Zhang, Y. J. Jiang and J. Q. Sun, Langmuir, 2016, 32, 3393.

$60 \mathrm{~J} . \quad$ L. Lutkenhaus, K. D. Hrabak, K. McEnnis and P. T. Hammond, J. Am. Chem. Soc., 2005, 127, 17228.

61 X. Wang, Y. Wang, S. Bi, Y. G. Wang, X. G. Chen, L. Y. Qiu and J. Q. Sun, Adv. Funct. Mater., 2014, 24, 403.

62 B. Thierry, P. Kujawa, C. Tkaczyk, F. M. Winnik, L. Bilodeau and M. Tabrizian, J. Am. Chem. Soc., 2005, 127, 1626.

63 H. F. Chuang, R. C. Smith and P. T. Hammond, Biomacromolecules, 2008, 9, 1660.

64 C. Monge, J. Almodóvar, T. Boudou and C. Picart, Adv. Healthcare Mater., 2015, 4, 811. 